\title{
Correction to: Funding of Professional Team Sports Organisations
}

Kim Lachmann and Johannes Struckmeier

\section{Correction to: \\ Chapter "Funding of Professional Team Sports \\ Organisations" in: S. Walzel and V. Römisch (eds.), Managing Sports Teams, Management for Professionals, https://doi.org/10.1007/978-3-030-56495-7_14}

In the original version of the book, the following belated correction incorporated: In chapter "Funding of Professional Team Sports Organisations", the author K. Lachmann's affiliation has been updated from "Deloite" to "Deloitte". The correction chapter and the book have been updated with the change. 